\title{
Le briquetage de la Seille, entre Marsal et Moyen- Vic (57)
}

\section{Laurent Olivier}

\section{(QpenEdition \\ Journals}

Édition électronique

URL : http://journals.openedition.org/adlfi/8608

ISSN : 2114-0502

Éditeur

Ministère de la culture

Référence électronique

Laurent Olivier, «Le briquetage de la Seille, entre Marsal et Moyen-Vic (57) », ADLFI. Archéologie de la France - Informations [En ligne], Lorraine, mis en ligne le 01 mars 2001, consulté le 03 mai 2019. URL http://journals.openedition.org/adlfi/8608

Ce document a été généré automatiquement le 3 mai 2019.

(c) Ministère de la Culture et de la Communication, CNRS 


\title{
Le briquetage de la Seille, entre Marsal et Moyen-Vic (57)
}

\author{
Laurent Olivier
}

Identifiant de l'opération archéologique : F1357200100159

Date de l'opération : 2001 (PT)

1 La campagne de terrain 2001 a été principalement consacrée à la réalisation d'une prospection géophysique héliportée de l'ensemble de la vallée supérieure de la Seille, entre les villages de Salonnes et de Mulcey, ainsi que du tracé de la vallée du ruisseau de Nard, au sud-est. Cette opération, réalisée en coopération avec le «Bureau des recherches géologiques et minières» (BRGM), a été confiée au "Service fédéral de recherches géophysiques et géologiques de Hanovre» (RFA). Entreprise sur une surface d'environ $70 \mathrm{~km}^{2}$, elle a permis de mettre en évidence la présence de très grandes accumulations de briquetage dans les secteurs de Marsal et de Moyenvic, ainsi que la présence d'anomalies massives étendues dans le secteur de Mulcey, dont l'origine reste à déterminer.

2 Les prospections géophysiques héliportées ont été couplées à des prospections systématiques au sol, combinées à des carottages systématiques dans certains secteurs de concentration d'ateliers de briquetage, notamment comme au « Pransieu » à Marsal. Ces travaux de reconnaissance ont permis d'identifier de nouveaux complexes d'ateliers, jusqu'ici inconnus, comme dans le secteur de Vic-sur-Seille «Le Châtry ». Ils ont permis également de recenser un total de plus d'une cinquantaine de sites, répartis du Néolithique au Moyen Âge, parmi lesquels de nombreuses découvertes inédites. 
INDEX

Index géographique : Lorraine, Moselle (57), Marsal

Index chronologique : âge du Bronze, âge du Fer

operation Prospection thématique (PRT)

Thèmes : atelier, briquetage du sel, four à sel, fourneau, prospection géophysique

\section{AUTEURS}

\section{LAURENT OLIVIER}

SDA 